\title{
PERANCANGAN GAME JALAK BALI BERBASIS ANDROID
}

\author{
I Nyoman Jayanegara, S.Sn., M,Sn \\ STMIK STIKOM Indonesia \\ Denpasar-Bali \\ 1980jayanegara@gmail.com
}

\section{Abstrak}

Jalak Bali merupakan burung endemik Indonesia yang hanya ada di Bali dan bahkan burung ini telah menjadi maskot dari pulau Dewata (Bali). Burung Jalak Bali mengalami penurunan populasi dan dikategorikan ke dalam satwa langka dan nyaris punah, sehingga keberadaannya dilindungi oleh Undang-Undang. Untuk itu perlu upaya untuk pelestarian Jalak Bali dengan langkah menumbuhkembangkan kecintaan anak-anak terhadap hewan ini melalui sebuah permainan (game). Game ini ditujukan pada anak-anak usia 9-12 tahundan bersifat edukasi, yang berisi pengenalan dari burung Jalak Bali khususnya tentang ciri-ciri, habitat, makanan dan pemangsanya.Game ini berbasis Android, dimana sistem operasi ini cukup besar pengggunanya di Indonesia.

Kata kunci :Game, Pelestarian, Jalak Bali, Android

\section{LATAR BELAKANG}

Burung Jalak Bali merupakan salah satu burung endemik Indonesia yang hanya ada di Bali bagian barat. Burung yang menjadi maskot provinsi Bali ini termasuk dalam kategori satwa langka dan nyaris punah sehingga keberadaannya dilindungi oleh Undang-Undang. Untuk itu perlu upaya untuk pelestarian Jalak Bali agar keberadaannya tidak sampai punah. Salah satu bentuk pelestarian burung Jalak Bali dapat melalui pengenalan sejak dini kepada anak-anak. Dengan pengenalan ini diharapkan tumbuh kecintaan anak-anak terhadap burung Jalak Bali itu sendiri. Salah satu media yang dapat digunakan untuk pengenalan burung Jalak Bali kepada anak-anak adalah melalui sebuah game yang bersifat edukasi dan berbasis Android.

Gamesendiri merupakan kata dalam bahasa Inggris yang berarti permainan. Permainan dalam hal ini merujuk pada pengertian kelincahan intelektual. Game juga dapat diartikan sebagai arena keputusan dan aksi permainannya, sehingga diharapkan mampu merangsang minat belajar anak.Dalam penggunaannya, saat ini kata game lebih mengacu kepada video game. Video gameadalah game berbasis

\author{
I WayanAdi Putra Yasa, S.Kom \\ STMIK STIKOM Indonesia \\ Denpasar-Bali \\ tactful@rocketmail.com
}

elektronik dan visual, yang hanya dapat dimainkan di media visual elektronik.

Game Jalak Bali yang akan dirancang ini berbasis Android, yang terdiri dari intro scene, scene edukasi, scene menu toko, level game, menu status, dan ending scene.Android itu sendirimerupakan sistem operasi berbasis linux yang diperuntukan untuk smartphone dan juga tablet. Android itu sendiri dikembangkan oleh Google dan bersifat open source. Di Indonesia sendiri, pengguna Android cukup banyak, dimanapada tahun 2013 dari bulan Januari sampai Maret mencapai 74,4 persen.

Atas dasar itulah akan dirancang sebuah game edukasi sebagai media alternatif pembelajaranyang menarik bagi anak-anak mengenai Jalak Bali berbasis Android, dimanagame ini diharapkan mampu mendukung program pelestarian burung Jalak Bali.

\section{TUJUAN PENELITIAN}

Adapun tujuan dari perancangan game ini yaitu:

1. Untuk merancang game Jalak Bali berbasis Android yang diharapkan mampu merangsang minat belajar anak.

2. Sebagai media edukasi dalam mengenalkan burung Jalak Bali kepada anak-anak berusia 9-12 tahun.

\section{LANDASAN TEORI}

\subsection{Game Edukasi}

Game edukatif adalah permainan yang telah dirancang untuk mengajar seseorang tentang topik tertentu atau membantu mereka dalam belajar suatu keterampilan sambil mereka bermain (Rachman, 2012:7). Berisi materi pendidikan yang dirancang dalam permainan interaktif yang bertujuan untuk meningkatkan kecerdasan. Elemen-elemen dimana konsep game edukatif berada berbasis pada konsep pendidikan dasar yang menggabungkan unsur-unsur yaitu: kreativitas, menyenangkan, petualangan, motivasi, bermain, keterampilan, bebas, mendidik, logika, kegemaran, mandiri, dan keputusan. Konsep 
ISSN 2087-2658

Jurnal Nasional Pendidikan Teknik Informatika (JANAPATI)

Volume 4, Nomor 1, Maret 2015

ini kemudian disesuaikan dengan klasifikasi usia pengguna dan kurikulum pembelajaran.

Game edukasi adalah game digital yang dirancang untuk pengayaan pendidikan (mendukung pengajaran dan pembelajaran), menggunakan teknologi multimedia interaktif. Menurut Widiastuti dan Setiawan, (2012:2) yang mengutip Hurd dan Jenuings menyatakan, perancang yang baik haruslah memenuhi kriteria dari education game itu sendiri. Berikut ini adalah beberapa kriteria dari sebuah education game, yaitu:

1. Nilai Keseluruhan (Overall Value)

Nilai keseluruhan dari suatu game terpusat pada desain dan panjang durasi game. Aplikasi ini dibangun dengan desain yang menarik dan interaktif. Untuk penentuan panjang durasi, aplikasi ini menggunakan fitur timer.

2. Dapat Digunakan (Usability)

Mudah digunakan dan diakses adalah poin penting bagi pembuat game. Aplikasi ini merancang sistem dengan interface yang user friendly sehingga user dengan mudah dapat mengakses aplikasi.

3. Keakuratan (Accuracy)

Keakuratan diartikan sebagai bagaimana kesuksesan model/gambaran sebuah game dapat dituangkan ke dalam percobaan atau perancangannya. Perancangan aplikasi ini harus sesuai dengan model game pada tahap perencanaan.

4. Kesesuaian (Appropriateness)

Kesesuaian dapat diartikan bagaimana isi dan desain game dapat diadaptasikan terhadap keperluan user dengan baik. Aplikasi ini menyediakan menu dan fitur yang diperlukan user untuk membantu pemahaman user dalam menggunakan aplikasi.

5. Relevan (Relevance)

Relevan artinya dapat mengaplikasikan isi game ke target user. Agar dapat relevan terhadap user, sistem harus membimbing mereka dalam pencapaian tujuan pembelajaran. Karena aplikasi ini ditujukan untuk anak-anak, maka desain antarmuka harus sesuai dengan nuansa anak-anak, yaitu menampilkan warna-warna yang ceria.

6. Objektifitas (Objectives)

Objektifitas menentukan tujuan user dan kriteria dari kesuksesan atau kegagalan. Dalam aplikasi ini objektivitas adalah usaha untuk mempelajari hasil dari permainan.

7. Umpan Balik (Feedback)

Untuk membantu pemahaman user bahwa permainan (performance) mereka sesuai dengan objek game atau tidak, feedback harus disediakan. Aplikasi ini menyajikan animasi dan efek suara yang mengindikasikan kesuksesan atau kegagalan permainan.

\subsection{Jalak Bali}

Jalak Bali (Leucopsar rothschildi) adalah salah satu contoh satwa langka dan endemik yang ada di Indonesia tepatnya di pulau Bali dengan sebaran terluasnya antara Bubunan Buleleng sampai ke Gilimanuk, namun pada saat ini semakin sempit, hanya terbatas pada kawasan Taman Nasional Bali Barat tepatnya di Semenanjung Prapat Agung dan Tanjung Gelap Pahlengkong.

3.2.1 Ciri-ciri Jalak Bali

Burung Jalak Bali memiliki ciri-ciri khusus, antara lain: (Laporan Monitoring Populasi Jalak Bali oleh BKSDA Bali)

1. Bulu seluruhnya putih kecuali ujung sayap dan ujung ekor yang berwarna hitam.

2. Matanya berwarna coklat tua, daerah sekitar kelopak mata tanpa bulu berwarna biru tua.

3. Jalak Bali memiliki jambul yang berupa beberapa helai bulu, jantan bentuknya lebih indah dan mempunyai jambul lebih panjang dari pada yang betina.

4. Kakinya berwarna abu-abu pucat dengan jari jemari yaitu satu kebelakang, dan tiga jari lainnya kedepan.

5. Paruh runcing dengan panjang $\pm 2-5 \mathrm{~cm}$, berbentuk khas yaitu dibagian atasnya terdapat peninggian yang memipih tegak. Warna paruh abu-abu kehitaman dengan ujung kuning kecoklatan.

6. Antara burung jantan dan betina sulit dibedakan, perbedaannya adalah bahwa yang jantan agak lebih besar dan memiliki kuncir yang agak panjang.

7. Jalak Bali bertelur 2-3 butir, berwarna biru.

\subsubsection{Sejarah Penemuan Jalak Bali}

Jalak Bali (Leucopsar rothschildi) pertama kali ditemukan oleh Dr. Baron Stressmann seorang ahli burung berkebangsaan Inggris yaitu pada tanggal 24 Maret 1911. Pada tahun 1925, Dr. Baron Victor Van Plessenn meninjau pulau Bali dan mengadakan penelitian lebih lanjut atas anjuran Dr. Stressmann, ia menemukan penyebaran Jalak Bali (Leucopsar rothschildi) mulai dari Desa Bubunan sampai dengan Gilimanuk dengan jumlah masih ratusan dan hidup berkelompok (berkoloni). Pada tahun 1928 sebanyak 5 (lima) ekor Jalak Bali (Leucopsar rothschildi) dibawa ke Inggris dan pada tahun 1931 telah berhasil berkembang biak. Pada tahun 1962 kebun binatang Sandiego di Amerika Serikat 
mengembangbiakan Jalak Bali (Seminar BKSDA Bali tahun 2011).

\subsubsection{Status Jalak Bali}

1. Sejak tahun 1966, IUCN (International Union for Conservation of Nature and Natural Resources) telah memasukkan Jalak Bali kedalam red data book, yaitu buku yang memuat jenis flora dan fauna yang terancam punah.

2. Pada konvensi perdagangan internasional bagi jasad liar CITES (Convention on International Trade in Endegered Species of Wild Flora and Fauna), Jalak Bali terdaftar dalam Appendix I, Yaitu kelompok yang terancam kepunahan dan dilarang untuk diperdagangkan.

3. Pemerintah Indonesia mengeluarkan Surat Kepmen. Pertanian Nomor 421/kpts/Um/70 tanggal 26 Agustus 1970, yang menerangkan antara lain bahwa Jalak Bali dilindungi.

4. Dikatagorikan sebagai satwa Endemik Bali karena Jalak Bali habitat aslinya hanya ada di pulau Bali tidak ada di habitat lainnya (saat ini ruang hunian menyempit hanya ada dikawasan Taman Nasional Bali Barat).

5. Oleh Pemerintah Daerah Propinsi Bali dijadikan sebagai fauna simbol Propinsi Bali.

\subsubsection{Habitat Jalak Bali}

Habitat burung Jalak Bali berada di kawasan Taman Nasional Bali Barat tepatnya di Semenanjung Prapat Agung dan Tanjung Gelap Pahlengkong. Habitatnya bertipe hutan mangrove, hutan pantai, hutan musim dan savana. Dihabitat aslinya burung Jalak Bali bersarang dengan meletakkan telurnya pada rongga-rongga pohon alami atau bekas sarang burung pelatuk. Predator dari burung Jalak Bali di habitat aslinya adalah biawak, ular dan elang yang merupakan predator alami dari beberapa jenis burung (Laporan Monitoring Populasi Jalak Bali oleh BKSDA Bali).

\subsubsection{Makanan Jalak Bali}

Di alam bebas, pakan alam yang dikonsumsi oleh Jalak Bali dalam meniti hidupan liarnya, antaralain untuk jenis pakan berkategori hewani terdiri dari: Semut, telor semut, belalang, jangkrik, ulat, kupu-kupu, rayap, dan serangga tanah. Untuk pakan berkategori nabati terdiri dari buah: kerasi (lamntana camara), bekul (Zyzyphus mauritiana), intaran (Azadirachta indica), daging buah kepuh (Sterculuia foetida), talok (Grewia koordersiana), trenggulun, buni (Antidesma bunius), kalak, ciplukan, kelayu.
Sedangkan makanan yang disajikan di penangkaran untuk kategori nabati antara lain pisang dan pepaya. Sedangkan untuk hewani terdiri dari ulat hongkong, belalang, jangkrik, dan kroto basah (telur semut). Jenis pakan pendukung lainnya yang disajikan yaitu jenis pakan olahan seperti kroto Kristal kroto voer 521, kroto fancy food. (www.tnbalibarat.com)

\section{METODE PERANCANGAN}

\subsection{Konsep Dasar Perancangan}

Konsep dasar merupakan langkah awal yang menjadi landasan pemikiran dari perancangan game Jalak Bali berbasis Android ini sampai pada tahap perwujudannya. Konsep perancangan merupakan hal yang penting karena merupakan dasar dalam merancang suaru media agar dalam proses perwujudannya nanti tidak keluar dari tujuan perancangan. Dalam perancangan geme Jalak Bali ini hal yang menjadi pertimbangan adalah game ini harus dapat menarik perhatian dari khalayak yang dituju, serta pesan yang ingin disampaikan agar tepat sasaran.

Adapaun konsep dari perancangan yang akan diterapkan adalah "fun" atau dapat berarti menyenangkan. Pemilihan konsep fun ini sesuai dengan tujuan dari sebuah game edukasi yaitu yang mengajak anak-anak untuk dapat memainkan game dengan perasaan yang menyenangkan serta mendidik dengan memberikan pengetahuan tentang burung Jalak Bali. Untuk menunjang penerapan konsep fun ini, penggunaan objek-objek multimedia sangat diperlukan dalam penyampainnya.

Pemilihan ilustrasi berupa kartun dengan pengambaran karakter yang sederhana dan mimik wajah yang tersenyum, penerapan warna-warna cerah seperti kuning, jingga, hijau dan biru. Menggunakan huruf Arial Rounded MT ExtraBold yang terkesan kartun dan mudah dibaca. Dengan penerapan pada elemen-elemen tersebut, diharapkan nantinya perancangan game ini dapat diterima oleh anak-anak sebagai media hiburan dan pengetahuan tentang burung Jalak Bali.

4.2 Skema Proses Perancangan

Adapun skema proses perancangan dari tema yang diangkat dalam merancang game Jalak Bali ini, yaitu : 
ISSN 2087-2658

Jurnal Nasional Pendidikan Teknik Informatika (JANAPATI)

Volume 4, Nomor 1, Maret 2015

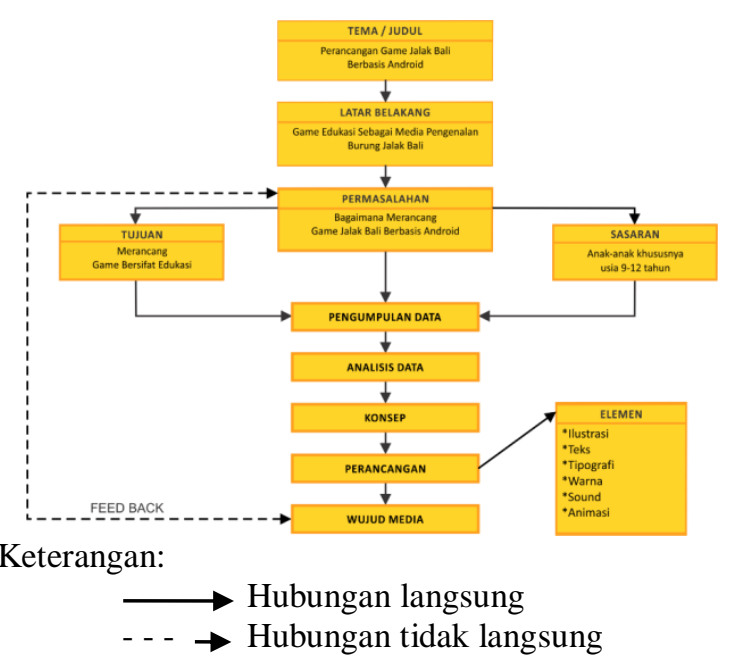

Gambar 6.1Skema Pola Perancangan

Dari skema proses perancangan diatas dapat diuraikan sebagai berikut: Dari tema atau judul yang diangkat munculah permasalahan yang harus dipecahkan. Dari rumusan masalah selanjutnya menentukan tujuan dan sasaran dari perancangan. Kemudian mengumpulkan data yang diperlukan untuk melakukan analisis data. Setelah melakukan analisis data akan didapat sebuah konsep dari perancangan dan elemenelemen yang digunakan. Bila konsep dan elemen-elemen telah ditentukan tahapan selanjutnya adalah melakukan perancangan media hingga berwujud.

\subsection{Strategi Visual}

Dalam perancangan game Jalak Bali berbasis Android tidak terlepas dari unsur-unsur visual untuk media penerapan konsep fun, berikut adalah implementasi dari unsur-unsur visual tersebut :

1. Ilustrasi

Ilustrasi yang digunakan pada game Jalak Bali ini adalah ilustrasi kartun karena ilustrasi kartun bersifat lucu. Dengan sifat lucu tersebut, diharapkan mampu membawa perasaan menyenangkan untuk anak-anak. Untuk dapat lebih menunjukkan perasaan menyenangkan, penggambaran ekpresi wajah dari karakter dibuat dengan ekspresi yang ceria yaitu dengan membuat karakter tersenyum.

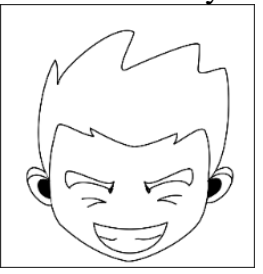

Gambar 6.2 Contoh expresi wajah ceria
2. Teks

Teks digunakan sebagai media untuk memberikan keterangan atau informasi. Adapun yang digunakan adalah headline, body copy dan closing word. Yang diterapkan pada story, help serta informasi dalam permainan.

\section{Tipografi}

Tipografi yang digunakan adalah jenis Sans Serif yaitu Arial Rounded MT ExtraBold dan Calibri. Arial Rounded MT ExtraBold dipilih karena memiliki kesan dinamis dan mudah dibaca, sedangkan Calibri dipilih karena huruf jenis ini mudah dikenali dan mudah pula untuk dibaca. Dengan ukuran huruf minimal 12 pt, agar memudahkan anak-anak dalam membacanya.

\section{Warna}

Warna yang digunakan pada game Jalak Bali ini adalah warna-warna cerah. Warna cerah dipilih karena memberikan kesan kebahagiaan dan kegembiraan. Adapun warna yang akan digunakan seperti warna, kuning, jingga, hijau dan biru. Serta tidak menutup kemungkinan menggunakan warna pendukung lainnya seperti coklat dan merah.

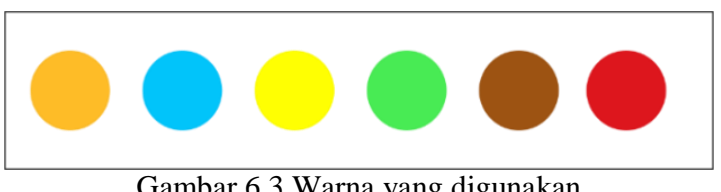

5. Sound

Sound diimplementasikan sebagai backsound pada тепи dan permainan mengumpulkan koin serta ketika tombol disentuh. Format sound yang akan digunakan adalah $\mathrm{mp} 3$, karena format mp3 memiliki ukuran file yang cukup kecil dengan kualitas yang baik.

6. Animasi

Animasi yang digunakan pada game Jalak Bali ini adalah animasi karakter, animasi sprite serta computation animation. Animasi karakter digunakan untuk membuat animasi karakter di adobe flash sedangkan animasi sprite dan computationanimation digunakan pada Corona.

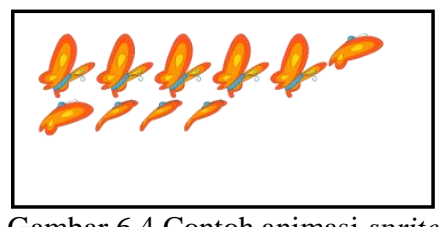

Gambar 6.4 Contoh animasi sprite

6.4 Strategi Kreatif

6.4.1 Isi Pesan 
Adapun isi pesan yang ingin disampaikan melalui game Jalak Bali ini adalah pengetahuan tentang burung Jalak Bali, ciri-ciri, makanan, pemangsa, habitat dan tahapan perkembangan dari burung Jalak Bali. Mulai dari anakkan hingga burung Jalak Bali dewasa dan siap untuk dibebaskan kembali ke alam. Selain itu, terdapat juga pesan yang memberitahukan anak-anak tentang pentingnya melestarikan burung Jalak Bali yang disampaikan melalui story telling.

\subsubsection{Bentuk Pesan}

Bentuk pesan yang ingin disampaikan pada game Jalak Bali ini adalah berupa teks dan ilustrasi, baik itu story maupun pengetahuan tentang Jalak Bali. Story disampaikan sebanyak dua kali, yaitu ketika memulai permainan dan akhir dari permainan. Sedangkan pengetahuan tentang Jalak Bali disampaikan ketika story awal melalui percakapan yang terjadi antara karakter.

\subsubsection{Storyline}

Game ini berlatar disebuah daerah dekat dengan habitat burung Jalak Bali, yang keberadaannya semakin langka karena penangkapan liar oleh tangantangan orang yang tidak bertanggung jawab. Didekat habitat tersebut tinggalah seorang anak yang bernama Putu (pemain) dan ayahnya yang peduli terhadap keberadaan burung Jalak Bali. Suatu ketika ia diajak oleh ayahnya untuk pergi kehutan. Sesampai dihutan ia dan ayahnya melihat induk Jalak Bali yang dimangsa ular dan berhasil menyelamatkan seekor anak Jalak Bali untuk dirawat dirumah. Untuk dapat merawat anakkan burung Jalak Bali, pemain ditugaskan memberinya energi. Energi dapat dibeli dengan poin yang harus dikumpulkan terlebih dahulu. Energi tersebut akan menambah tenaga burung dan ketika mencapai batas yang ditentukan barulah burung Jalak Bali dapat melewati tahap perkembangannya dan siap untuk dibebaskan kembali. Game akan berakhir ketika burung sampai pada level 15.

\subsubsection{Storyboard}

Storyboard adalah sketsa gambar yang disusun berurutan sesuai naskah, storyboard dapat menyampaikan ide cerita kepada orang lain dengan lebih mudah, karena dapat menggiring khayalan seseorang mengikuti gambar-gambar yang tersaji, sehingga menghasilkan persepsi yang sama pada ide cerita. Berikut merupakan storyboard dari game Jalak Bali ini :

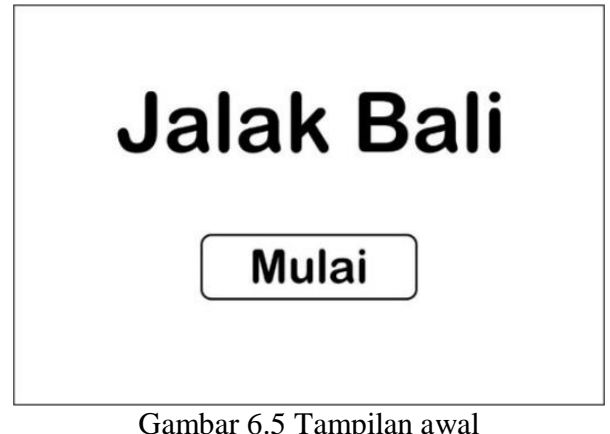

Gambar 6.5 merupakan tampilan awal ketika game ini dimulai, terdapat judul dari game ini, yaitu Jalak Bali. Dibawahnya terdapat tombol mulai yang mengarahkan pemain pada story dan menu utama.

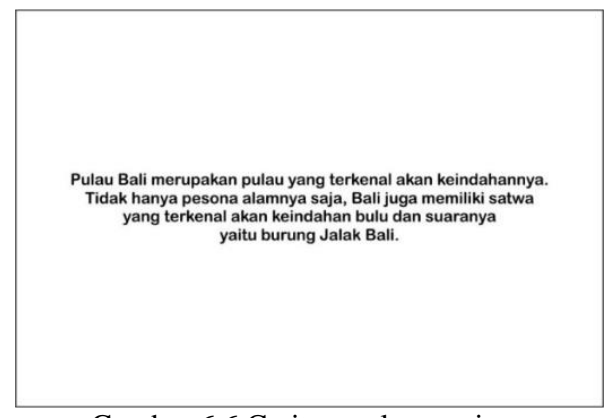

Gambar 6.6 Cerita awal permainan

Gambar 6.6 merupakan tampilan dari introscene sebagai cerita awal dari game. Berupa teks dan title dari game.

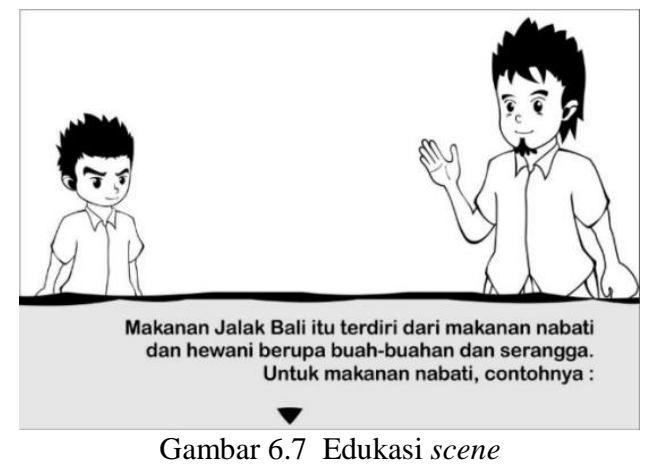

Gambar 6.7merupakan tampilan dari edukasi yang berupa percakapan yang terjadi antara karater utama (Putu) dan ayahnya. 


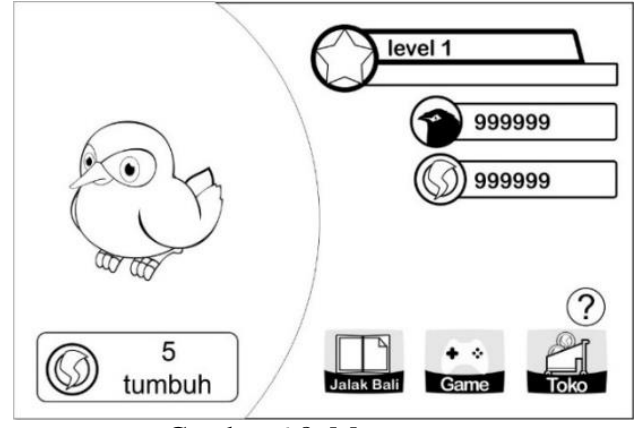

Gambar 6.8 Menu status

Gambar 6.8merupakan tampilan dari menu status yang menampilkan level burung, jumlah poin dan energi yang dimiliki pemain, serta terdapat beberapa tombol untuk mengarah pada toko, game, edukasi, dan help yang berupa panduan permainan.

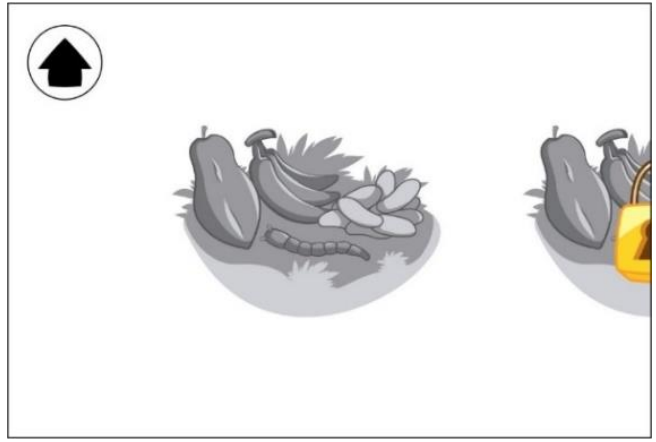

Gambar 6.9Scenelevel menu

Gambar 6.9 merupakan tampilan dari scenelevel menu, disini terdapat 4 arena, awalnya terdapat satu arena yang terbuka, apabila level burung telah mencapai level tertentu maka arena lainnya akan terbuka. Untuk melihat level lain, pemain dapat menggeser ke kiri atau ke kanan.

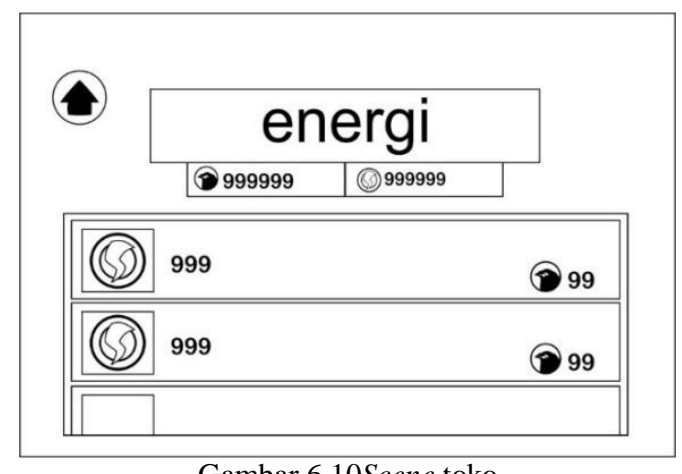

Gambar 6.10Scene toko

Gambar 6.10 merupakan tampilan dari menu toko yang menjual energi. Terdapat beberapa energi dengan nilai yang berbeda dan harga yang berbeda juga, awal permainan akan terbuka 3 saja, tetapi ketika burung mencapai level tertentu energi lain akan terbuka.

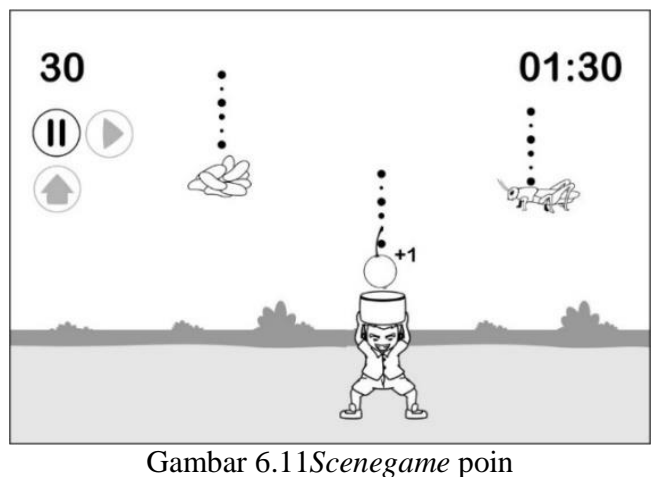

Gambar 6.11 merupakan tampilan menu game poin, yaitu dengan mengumpulkan makanan Jalak Bali yang berjatuhan dari atas, pada beberapa arena akan terdapat predator dari sebagai rintangan yang juga akan jatuh dari atas, apabila itu diambil dapat mengurangi poin. Untuk menggerakan karakter, pemain dapat mengerakkan ke kiri atau ke kanan.

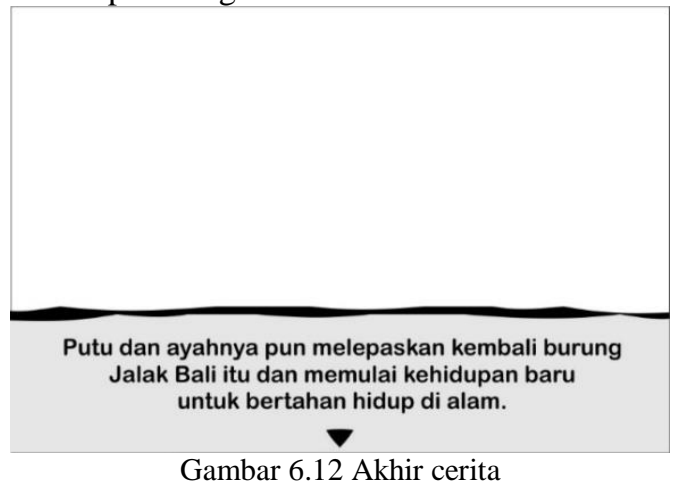

Gambar 6.12 merupakan tampilan dari akhir cerita dari geme, berupa percakapan antara karakter dan narasi penutup.

6.4.5 Gameplay

Misi dalam game Jalak Bali ini adalah memelihara burung Jalak Bali hingga tumbuh dewasa dan siap untuk dibebaskan kembali. Karakter pemain memulai permainan dengan jumlah poin 0 , energi yang dimiliki 0, Jalak Bali masih berupa anakkan, energi yang dibutuhkan 5 dan level burung 1. Level burung akan bertambah setelah diberi energi empat kali sesuai dengan kebutuhan dan akan dikalikan dua setiap naik level. Untuk mendapatkan energi, pemain harus mengumpulkan poin terlebih dahulu pada game lain, setelah itu membeli energi dengan poin yang telah dikumpulkan. Dalam pengumpulan poin ini, 
makanan Jalak Balu akan berjatuhan dari atas dan pemain akan bergerak ke kiri dan ke kanan untuk mengumpulkannya selama 2 menit. Untuk menyelesaikan game ini burung harus mencapai level 15.

\subsubsection{Struktur Game}

Game ini dimulai dari menu awal, disini terdapat kondisi apabila pemain baru pertama kali memainkan game ini maka, sistem akan membuat serta menyimpan data baru dan berpindah pada sceneintrostory, edukasi scene dan akhirnya sampai pada menu status. Namun, apabila pemain sudah permain memainkan game maka dari pemain akan di arahkan langsung pada menu status. Dari menu status ini dapat berpindah ke menu toko, levelgame dan edukasi. Apabila kondisi telah terpenuhi maka dari menu status akan menuju ke endingscene. Dari endingscene akan kembali lagi ke menu awal untuk dapat memaikan permainan lagi dari awal. Hal ini dapat dilihat pada gambar 6.13 di bawah ini.

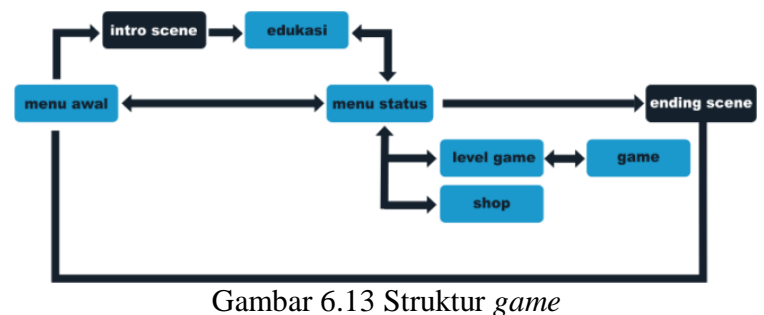

\subsubsection{Perangkat Keras}

Adapun spesifikasi minimum yang dapat digunakan untuk pembuatan game Jalak Bali ini sebagai berikut : 1) Personal computer INTEL Pentium 4, $2.4 \mathrm{GHz}, 2)$ RAM 512 Megabyte, 3) Harddisk 90 Gigabyte, 4) Mobile INTEL 4 series expres chipset family.

\subsubsection{Perangkat Lunak}

Perangkat lunak yang digunakan dalam merancang game Jalak Bali ini adalah sebagai berikut

\section{Sistem operasi Windows XP}

Windows merupakan serangkaian sistem operasi yang diproduksi oleh Microsoft untuk digunakan pada komputer pribadi. Windows XP sendiri adalah nama dari versi Microsoft Window, yang digunakan penulis dalam perancangan game ini.

\section{CorelDraw}

CorelDraw merupakan perangkat lunak olah grafis berbasis vector, yang memungkinkan pengguna mengelola grafis tanpa dibatasi seberapa besar ukuran objeknya. Dengan demikian, walau objek grafis dibuat lebih besar atau lebih kecil sesuai kebutuhan, kualitas imageakan tetap dipertahankan.Tidak hanya kemampuan merancang grafis, CorelDraw memiliki berbagai kelebihan dan fitur lainnya, karena perangkat lunak ini dilengkapi dengan berbagai ToolEditing untuk mengelola dan memodifikasi berbagai atribut objek grafis seperti: tingkat kontras, colorbalance, menambahkan berbagai efek khusus, juga mengubah format warna dari RGB menjadi CMYK, dan masih banyak lagi (Sulianta, 2011:1).

3. Adobe Flash

Dikutip dari Sunyoto (2010:1), perangkat lunak Adobe Flash yang selanjutnya disebut Flash, dulunya bernama "Macromedia flash" merupakan software multimedia unggulan yang dulunya dikembangkan oleh macromedia, tetapi sekarang dikembangkan dan didistribusikan oleh Adobe System. Sejak tahun 1996, flash menjadi metode popular untuk menambahkan animasi, hiburan dan berbagai komponen web, diintregasikan dengan video dalam halaman web sehingga dapat menjadi aplikasi multimedia yang kaya (RichInternetApplication).

Flash dapat digunakan untuk memanipulasi vector dan citra raster, dan mendukung bidirectionalstreaming audio dan video. Flash juga berisi bahasa skrip yang diberi nama "ActionScript". Beberapa produk software, system dan device dapat membuat dan menampilkan isi flash. Flash dijalankan dengan Adobe Flash Player yang dapat ditanam pada browser, telepon seluler, atau software lain. File format flash adalah SWF, biasanya disebut "ShockWaveFlash" movie.

Dalam perancangan game ini, adobe flash digunakan untuk membuat dasar animasi sprite, seperti pembuatan animasi karakter burung Jalak Bali dan karakter pemain. Selain itu, dengan adanya systemlayer serta tween membuat proses penggerakkan animasi menjadi lebih mudah untuk pembuatan animasi 2D.

4. Corona SDK

Corona SDK adalah Software Development Kit yang dikembangkan oleh Walter Luh, pendiri Corona Labs Inc (sebelumnya dikenal sebagai Ansca Mobile). Corona memungkinkan programmer perangkat lunak untuk dengan mudah membangun aplikasi mobile untuk iPhone, iPad, dan perangkat Android (coronalabs.com). Bahasa yang dipakai adalah bahasa Lua.

Penulis menggunakan Corona karena adanya fitur build-in emulator yaitu dengan menampilkan visualisasi dari aplikasi sesuai dengan tampilan serta ukuran dari beberapa smartphone, tanpa perlu 
melakukan rebootingemulator dan compileprogram saat proses pembuatan aplikasi. Selain itu dengan adanya fitur garbage collector, Corona menjadikan aplikasi yang di buat menjadi cukup ringan untuk mampu dijalankan pada smartphone yang memiliki spesifikasi rendah.

5. Spritelog

Spriteloq adalah sebuah program pembuat spritesheet dengan cara meng-import animasi $S W F$ dari Flash agar dapat digunakan dalam Corona (loqheart.com). Spriteloq merupakan sebuah software tambahan yang diperuntukkan untuk Corona SDK yang mampu mengubah animasi Flash menjadi spritesheet dan code berupa file Lua, yang dapat langsung digunakan pada Corona.

6. Notepad++

Notepad++ adalah sebuah program freeware yang berfungsi sebagai editor pengganti notepaddefault bawaan Windows. Notepad++ ditulis dalam $\mathrm{C}++$ yang menjamin kecepatan eksekusi lebih tinggi dan ukuran program yang lebih kecil (Kurniawan, 2010:109). Berikut ini beberapa keunggulan Notepad++ dibandingkan dengan Notepad standar:

a. Tampilan lebih menarik dan menyegarkan.

b. Lebih userfriendly dan mudah penggunannya.

c. Mendukung multi tab.

d. Mendukung banyak bahasa pemrograman seperti ActionScript, Ada, ASP, Assembler, autoIt, C, C++, C\#, Caml, Cmake, COBOL, CSS, LISP, Lua, Pascal, Perl, PHP, Postscript, PowerShell, Properties file, Python.

7. Pada dasarnya Corona merupakan sebuah emulator yang tidak memiliki editor khusus, maka daripada itu penulis menggunakan Notepad++ sebagai editor karena sifatnya yang freeware serta mendukung bahasa Lua.

8. Adobe Audition

Adobe Audition adalah program produksi dari Adobe Corporation untuk mengedit file-file audio, aplikasi ini dapat diintegrasi dengan berbagai program lain dari Adobe. Edisi terbaru Adobe Audition memiliki kinerja yang cepat, Direct-to-File Recording, jumlah track yang tak terbatas, dukungan format video, tampilan Spectral Pan dan phase, $C D$ Audio Burning, Adobe Bridge, dan dukungan ASIO. (Redaksi Kawan Pustaka, 2008:60). Pemilihan penggunaan software ini karena Adobe Audition memiliki interface yang cukup mudah dimengerti, dan banyaknya jenis konversi audio serta efek yang dapat digunakan.

6.4.9 Implementasi Sistem
Agar dapat menjalankan game Jalak Bali ini dengan baik, terdapat syarat minimal smartphone Android, yaitu 1) Android version 2.3 (Gingerbread), 2) Screen resolution $320 \times 480$ piksel, 3) Processor $1 \mathrm{GHz}, 4)$ RAM 256MB dan 5) Memory 50MB.

\section{IMPLEMENTASI}

Dalam merancang game Jalak Bali terdapat prosedur yang harus dilewati hingga menjadi sebuah aplikasi, adapun tahapan-tahapan dari proses tersebut, yaitu :

1. Perancangan Aset Game

Pada pengerjaan game ini, diawali dengan pembuatan desain yang nantinya akan menjadi aset dalam proses animasi dan game, seperti karakter, background, dan userinterface yang semua dikerjakan secara digital menggunakan software CorelDraw X6.

2. Animasi

Proses pembuatan animasi dikerjakan dengan mengunakan software Adobe Flash CS6. Namun, pertama yang harus dilakukan adalah memisahkan bagian-bagian yang akan menjadi animasi pada CorelDraw X6 dan menyimpannya dengan format file SWF. Setelah itu animasi dikerjakan di software Adobe Flash CS6dengan mengunakan classic tween dan memberikan key frame pada bagian yang akan berganti. Atur panjang frame yang digunakan agar animasi terlihat rapi dan halus.Tahap selanjutnya adalah convert animasi yang telah selesai dibuat menjadi file lua agar dapat di-input pada Corona SDK dengan mengunakan Spritelog.

3. Publishing

Langkah terakhir dalam pembuatan game ini adalah proses publish agar game ini dapat dijalankan pada smartphone, khususnya smartphone yang berbasis Android. Proses publishing dilakukan dengan menggunakan Corona SDK dan telah tersambung dengan internet, dan memiliki akun Corona SDK.

4. Hasil Perancangan

Setelah melewati tahap perancangan dan melakukan proses publishing, selanjutnya adalah hasil akhir dari game Jalak Bali ini, adapun hasilnya adalah sebagai berikut:

A. Menu Awal

Tampilan dari menu awal game ini (gambar 7.1), dengan background berwarna biru serta terdapat beberapa pohon yang memberikan pemandangan hutan. Pada bagian tengah, terdapat title dari game 
Jalak Bali ini serta teks sebagai tanda untuk memulai permainan.

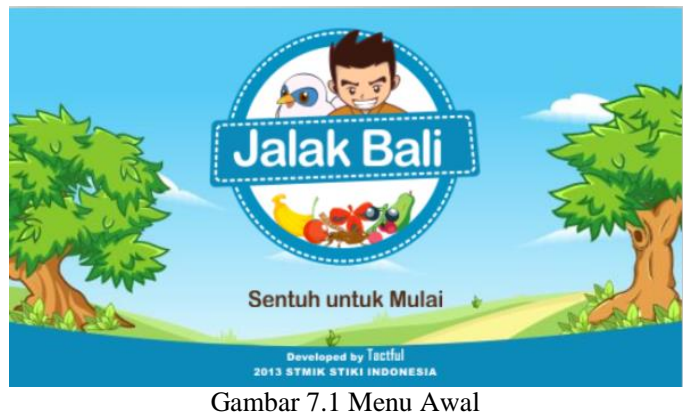

B. Intro Scene

Intro scene(gambar 7.2) yang merupakan tampilan ketika pertama kali memainkan game. Intro scenemenggunakan background berwarna biru dan pada bagian tengah terdapat sinopsis dari game Jalak Bali.

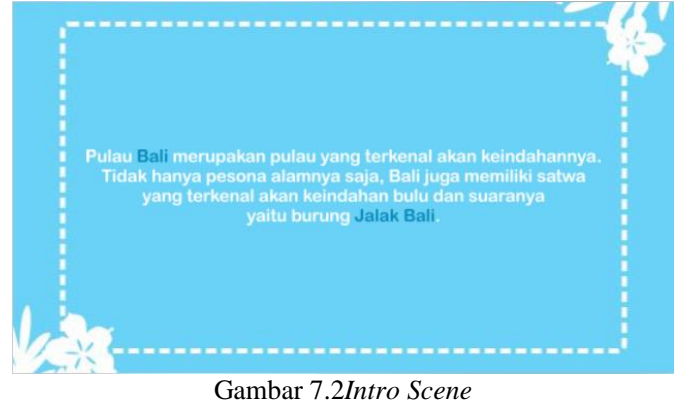

\section{Edukasi Scene}

Edukasi scene yang berupa storytelling.Pada scene ini dibagi menjadi dua bagian yaitu untuk penempatan teks dengan background biru dan penempatan objek yang dijelaskan dengan warna cokelat muda. Pada gambar 7.3, merupakan tampilan ketika memberikan penjelasan tentang makanan burung Jalak Bali. Untuk dapat melanjutkan membaca cerita, pemain dapat menekan bagian backgroundberwarna biru. Saat itu juga informasi yang diberikan juga akan berganti pada informasi selanjutnya.

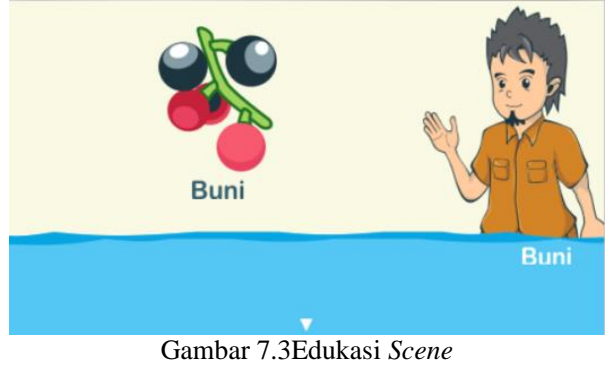

D. Menu Status

Pada menu ini (gambar 7.4 ) menunjukkan perkembangan dan level dari burung Jalak Bali. Bila pemain telah mencapai level yang telah ditentukan anakkan burung akan berganti menjadi burung remaja. Jumlah poin dan energy yang dimiliki juga dapat dilihat pada menu ini pada bagian kanan. Sedangkan energi yang diperlukan untuk tumbuh dapat dilihat pada bagian pojok kiri bawah yang nilainya akan bertambah ketika burung nail level. Selain itu terdapat juga beberapa tombol yang menuju pada beberapa scene, seperti edukasi, levelgame, toko dan juga bantuan berupa panduan untuk memainkan game ini.

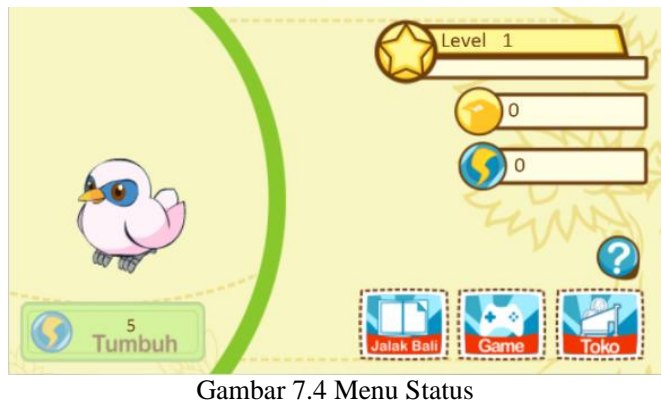

E. Level Game

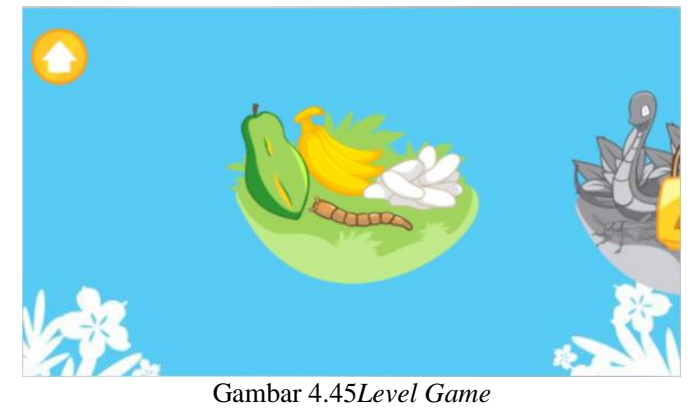

Gambar 4.45 diatas, adalah tampilan pada levelgamedengan background berwarna biru. Terdapat empat arena permainan di sini namun,akan terbuka hanya satu pada awal permainan. Tiga arena 
ISSN 2087-2658

Jurnal Nasional Pendidikan Teknik Informatika (JANAPATI)

Volume 4, Nomor 1, Maret 2015

lainnya akan terbuka ketika burung mencapai level yang telah ditentukan. Untuk melihat arena yang lain, pemain dapat menggeser ke kiri ataupun ke kanan pada layar. Dengan menyentuh simbol dari masingmasing arena pemain akan diarahkan pada game untuk mengumpulkan poin.

\section{F. Menu Toko}

Menu toko (gambar 7.6) dengan warna background berwarna biru, yang merupakan tempat untuk membeli energi yang diperlukan. Ketika awal permainan hanya tiga energi yang tersedia, sedangkan sisanya akan terbuka bila pemain mencapailevel tertentu. Untuk melihat energi lainnya, pemain dapat menyentuh pada bagian energi dan menggeser ke atas. Pada scene ini juga diberikan jumlah poin dan energi yang dimiliki oleh pemain.

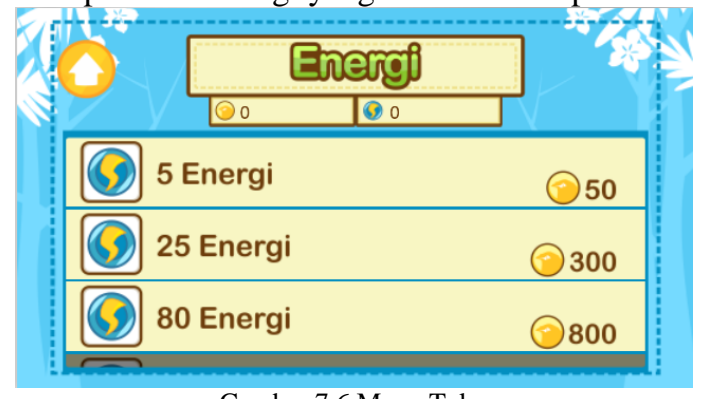

Gambar 7.6 Menu Toko

\section{G. Arena Game Poin}

Pada game pengumpulan poin (Gambar 7.7), makanan Jalak Bali akan berjatuhan dari atas dan pemain akan mengumpulkannya dengan bergerak ke kiri dan ke kanan dalam waktu dua menit. Masingmasing makanan memiliki nilai yang berbeda, pada beberapa arena terdapat juga predator dari burung Jalak Bali yang akan mengurangi poin bila mengambilnya. Pada masing-masing arena background yang dipakai berbeda begitu juga makanan yang berjatuhan. Pada bagian kiri terdapat tombol pause yang apabila disentuh akan muncul tombol lainnya seperti tombol kembali ke menu status, level game atau melanjutkan permainan kembali.

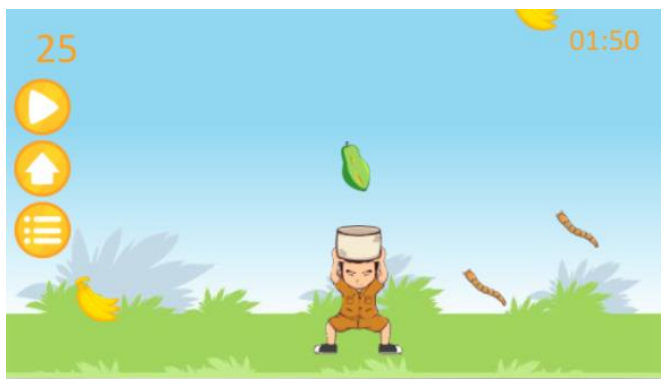

Gambar 7.7 Game Poin

\section{H. Ending Scene}

Pada ending scene(gambar 7.8) ini, tampilan hampir sama pada edukasi scene. Terdapat bagian yang menunjukkan background dan bagian penempatan teks.

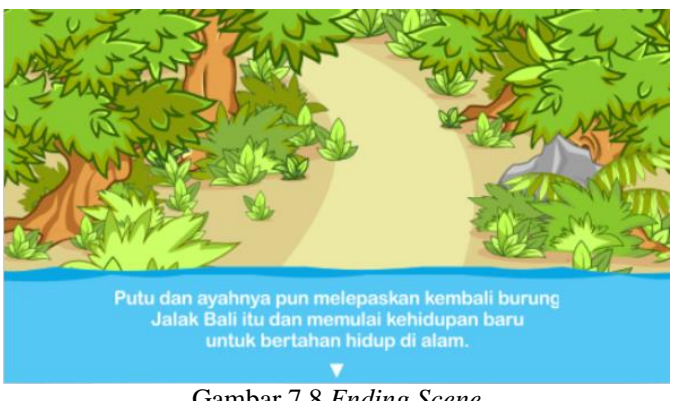

I. Pengujian

Dalam tahap ini pengujian akan dilakukan untuk melihat fungsi dari button pada masing-masing scenedalam aplikasi, dimana pengujian akan dilakukan oleh peneliti sendiri. Layout buttonpada scene dalam perancangan game ini, dapat dibagi menjadi 3 bagian yaitu : 1) Scene yang hanya merespon button hanya pada bagian bawah pada layar, seperti pada intro scene, scene edukasi serta ending scene, 2) Scene yang hanya merespon button pada bagian sebelah kiri dan kanan layar seperti pada arena game poin,3) Scene yang hanya merespon button sesuai dengan simbol-simbol yang dibuat seperti pada menu awal, menu status dan level game. Hasil pengujian dapat dilihat pada tabel 5.1.

Tabel 5.1 hasil pengujian

\begin{tabular}{|l|l|c|c|}
\hline No & \multicolumn{1}{|c|}{ Scene } & Layout Button & Berfungsi \\
\hline 1 & Menu Awal & $\begin{array}{c}\text { Symbol untuk } \\
\text { mulai }\end{array}$ & Ya \\
\hline 2 & Intro scene & Bawah layar & Ya \\
\hline 3 & Edukasi Scene & Bawah layar & Ya \\
\hline 4 & Menu status & Symbol & Ya \\
\hline 5 & Level game & Symbol & Ya \\
\hline 6 & Menu toko & Symbol & Ya \\
\hline 7 & Game poin & $\begin{array}{c}\text { Kanan-kiri } \\
\text { layar }\end{array}$ & Ya \\
\hline 8 & Ending scene & Bawah layar & Ya \\
\hline
\end{tabular}

Berdasarkan hasil pengujian pada tabel 5.1, didapat analisis, bahwa semua button bekerja dengan baik dan sesuai dengan kebutuhan pada saat aplikasi dijalankan.

\section{KESIMPULAN}

1. DalammerancanggameJalak Bali initerdapattahapan-tahapan yang 
ISSN 2087-2658

Jurnal Nasional Pendidikan Teknik Informatika (JANAPATI)

Volume 4, Nomor 1, Maret 2015

harusdilewatimulaidarimencari ide yaitudengan pertama kali mencariliterature, kemudianmengumpulkan informasi tentang Jalak Bali dan menentukankonsep perancangan, pembuatan desain, animasi scriptingdan publishing.

2. Pengetahuan yang diberikan berupa percakapan antar tokoh diharapkan anak-anak tertarik untuk mengetahui tentang burung Jalak Bali. Serta dengan game didalamnya dapat dilihat seberapa jauh anak-anak mengetahui tentang informasi yang disampaikan.

3. Berdasarkan pengujian, bahwa buttonpada aplikasi sudah berjalan sesuai dengan kebutuhan.

\section{DAFTAR PUSTAKA}

1. Ariyus, Dony. 2009. Keamanan Multimedia. Yogyakarta: Andi Offset.

2. Arnaya, I,B, Made dan Rohman, Fathur. 2010. Laporan Monitoring Populasi Jalak Bali Hasil Pelepasliaran Begawan Foundation di Pulau Nusa Penida, Kab. Klungkung. Denpasar: BKSDA Bali.

3. Binanto, Iwan. 2010. Multimedia Digital - Dasar Teori dan Pengembangannya. Yogyakarta: Andi Offset.

4. Gondo, S, Hut \& Sugiarto. 2013.DinamikaPopulasiJalak Bali (Leucopsarrothschildi) Di $\quad$ Habitatnya. http://www.tnbalibarat.com/.

5. Rachman I, Sielvia. 2012. Perancangan Mobile Game Edukatif "MewarnaiGambar" dengan Adobe Flash Cs5. http://repository.amikom.ac.id/files/publikasi_08.11.2178.pdf

6. Sarwono, Jonathan danLubis, Hari. 2007. MetodeRisetuntukDesainKomunikasi Visual. Yogyakarta: Andi.

7. Suyanto, M. 2004. Analisis\&DesainAplikasi Multimedia untukPemasaran. Yogyakarta: Andi Offset.

8. Widiastuti N, IndrianidanSetiawan. Irwan. 2012 Membangun Game EdukasiSejarahWalisongo. http://komputa.if.unikom.ac.id/_s/data/jurnal/volume-1-2/6komputa-1-2-game-edukasi-walisongo-nelly.pdf/pdf/6-

komputa-1-2-game-edukasi-walisongo-nelly.pdf. 